\title{
Comprehensive utilization of Aspergillus niger mycelium waste from citric acid fermentation on the basis of steam explosion and ionic liquid pretreatment
}

\section{Qinyuan Ma}

Tianjin University of Science and Technology

\section{Xiuzhen Gao}

Shandong University of Technology

\section{Xinyu Bi}

Tianjin University of Science and Technology

Menglei Xia

Tianjin University of Science and Technology

Qi Han

"RMIT University"

\section{Mingmeng Peng}

Tianjin University of Science and Technology

\section{Linna Tu}

Tianjin University of Science and Technology

\section{Yupeng Yang}

Tianjin University of Science and Technology

\section{Yanbing Shen}

Tianjin University of Science and Technology

min wang ( $\nabla$ minw@tust.edu.cn )

Tianjin University of Science and Technology

\section{Research}

Keywords: Chitosan, Fermentation residue, Steam explosion, Ionic liquid, Citric acid

Posted Date: December 16th, 2019

DOl: https://doi.org/10.21203/rs.2.18638/v1

License: (c) (i) This work is licensed under a Creative Commons Attribution 4.0 International License. Read Full License 
Page $2 / 20$ 


\section{Abstract}

\section{Background}

Aspergillus niger mycelium waste, a by-product from citric acid fermentation is considered a good raw material to produce fungal chitosan and glucosamine (GIcN). However, its successful application has always been a challenge.

Results

In this work, the effects of combined pretreatment involving steam explosion and ionic liquid (IL) on mycelium waste were investigated. Results show that pretreatment of mycelium waste at $2.5 \mathrm{MPa}$ for 1 min improved the GlcN hydrochloride yield by $65.49 \%$, the release of soluble sugar reached $0.46 \mathrm{~g} / \mathrm{g}$ of sample, and the deacelation degree of fungal chitosan by hydrolysis of chitin deacetylase from Rhodococcus equi CGMCC14861 (ReCDA) was from scratch and a 1.3-fold increase by combined with IL pretreatment. In addition, a recycling strategy for by-products, which promoted the fermentation of ReCDA used for fungal chitosan, was efficiently developed.

\section{Conclusion}

This is the first report of comprehensive utilization of Aspergillus niger mycelium waste from citric acid fermentation on the basis of steam explosion and ionic liquid pretreatment. This study demonstrates a green-like technology for the comprehensive utilization of A. niger mycelium waste from citric acid fermentation.

\section{Background}

Citric acid is the most important organic acid produced by fermentation. After citric acid fermentation, a large amount of Aspergillus niger (A. niger) mycelium waste is produced. This waste contains corn fibers and residual corn protein (The main composition of the mycelium waste was shown in supplementary table1). According to statistics, approximately 0.15 tons of dry mycelia is generated in each ton of citric acid produced. Global production of citric acid is currently estimated to exceed 2 million tons per year [1], which means that around 0.3 million tons of $A$. niger mycelia is generated per year. Usually, the waste is used as feed for ruminant animals. However, this type of disposal is low-value.

Approximately $15 \%$ chitin is present in the dried cell wall of $A$. niger mycelia [2]. Therefore, $A$. niger mycelia are good raw materials for the production of chitin and its derivatives, including chitosan, chitoologomers, N-acetyl-D-glucosamine (GIcNAc), and glucosamine (GIcN), which have a wide range of applications in biomedical, food, healthcare, and cosmetics industries [3-5]. As an eco-friendly approach, enzymatic hydrolysis for the production of chitin derivatives has attracted increasing attention [6, 7]. Cai et al. extracted chitosan from $A$. niger mycelia with lysozyme, snailase, neutral protease, and novel chitin deacetylase (CDA) [8]. CDA is the enzyme that catalyzes the deacetylation of the GlcNAc units of chitin to 
produce chitosan and exists in several fungi and bacteria $[9,10]$. However, the production of chitosan or GlcN via an enzymatic approach remains challenging. One of the main reasons is that chitin is not soluble due to its crystalline nature $[11,12]$. Therefore, on the basis of biomass utilization approaches, pretreatment methods should be developed to alleviate the crystalline structure of chitin before the biotransformation to chitosan and its derivatives.

Compared with other pretreatment methods, steam explosion (SE) is considered for many years as one of the most efficient and economic pretreatment technologies employed in the industrial scale [13, 14]. SE can be used in the pretreatment of many materials, such as hemicellulose [15], lignocellulose, lignin [16, 17], chitin [18], and corncobs (Teng et al., 2010). The pretreated material becomes porous and accessible to subsequent enzymatic hydrolysis. In addition, the use of ionic liquids (ILs) for cellulose and chitin pretreatment has also been increasingly recognized as a novel, efficient, and environment-friendly approach for biomass deconstruction $[19,20]$. Some ILs can influence the activity and stability of enzymes [21-23]. IL pretreatment can reduce the crystallinity of biopolymers, improving the surface area, porosity, and accessible binding sites during enzymatic catalysis [24].

To date, no attempt has been made in utilizing residual fibers, proteins, and mycelia in the mycelium waste from citric acid fermentation by SE combined with ionic liquid treatment, which needs to be discussed and solved especially in the current situation of environmental protection. At present, corn is used as a raw material for industrial production of citric acid [25]. Thus, there are a large amount of corn husks exist in mycelium waste, including $382 \mathrm{~g}$ of cellulose, $445 \mathrm{~g}$ of hemicellulose, $66 \mathrm{~g}$ of lignin, $19 \mathrm{~g}$ of protein, and $28 \mathrm{~g}$ of ash per $\mathrm{kg}$ of dry matter [26]. Hence, macromolecules, including chitin and cellulose, should be focused to comprehensively recycle mycelium waste. And, the structure composition of chitin is very similar to cellulose, which is reasonable to treat them at the same conditions and the treatment also can reduce resource utilization cost. In this study, SE and IL treatment was used in pretreating mycelium waste for the first time. First, the optimum conditions of SE toward mycelium waste were investigated. Then, SE and IL were used in the pretreatment of mycelium waste. The effect of combined pretreatment on enzymatic hydrolysis by cellulase and CDA was evaluated. This study demonstrates a possible approach for utilizing the soluble components and mycelia of waste from citric acid fermentation industry.

\section{Results And Discussion}

\section{Understanding the structural and chemical changes of mycelium waste following SE pretreatment}

Initially, optimization experiments of SE pretreatment were performed. Then, the pretreated waste was divided into two parts: solid content containing mycelia and cellulose and soluble components released by $A$. niger containing sugar and proteins. Both components were analyzed to evaluate the effect of SE on the mycelium waste.

\section{Structural changes and morphological properties of mycelium waste after SE}


Changes of various pretreated mycelium waste were analyzed after SE pretreatment. Fig. 1 shows the changes of color, shape, and particle size of materials pretreated by SE. With the increase of SE pressure from 1.0 MPa to 2.5 MPa, the color of materials gradually deepened (Fig. 1(A)). Meanwhile, the proportion of small particles increased remarkably above 1.5 MPa of SE, (Fig. 1(B)), and the differential pore increased remarkably at 2-10 $\mathrm{nm}$ (Fig. 1(C)). These changes indicate that SE showed a positive effect on the expansion and crushing of citric acid fermentation residues, which is consistent with a previous report [27]. But, it is difficult to recognize A. niger mycelia in figure 1(B), which may be due to the industrialization process of fermentation residue of citric acid including high temperature sterilization, plate frame filtration and full washing.

X-ray diffraction (XRD) analysis showed that the diffraction peaks at $19^{\circ}-20^{\circ}$ were obviously stretched, indicating the perceptible changes of the crystal structure of materials during SE treatment (Fig. 2(A)) [28]. Fig. 2(C) shows the comparative analysis of $A_{1560} / A_{1070}$ from Fourier-transform infrared (FT-IR) data (Fig. 2(B)). The deacetylation degree (DD) of chitin could be estimated by FT-IR spectra using two peaks associated with the $\mathrm{C}-\mathrm{O}$ stretching band of the acetamide group $\left(1070 \mathrm{~cm}^{-1}\right)$ and the amide II band of amino and acetamide groups $\left(1560 \mathrm{~cm}^{-1}\right)$ [29]. The $A_{1560} / A_{1070}$ value of samples treated under 2.0 and $2.5 \mathrm{MPa}$ decreased from 0.69 of the control to 0.61 and 0.60 , respectively, indicating that partial deacetylation of chitin from mycelium waste of citric acid fermentation occurred above 2.0 MPa of SE, which is consistent with other reports $[29,30]$.

To further characterize the effect of SE, the solid content produced after pretreatment was set as starting materials for the extraction of GIcN by hydrochloric acid (30\%). As shown in Table 1, the yield of GlcN hydrochloride increased with the increase of pressure. Under pretreatment pressure of $2.5 \mathrm{MPa}$, the yield of GlcN hydrochloride increased from $0.88 \mathrm{wt} \%$ solid content to $1.46 \mathrm{wt} \%$ solid content with a growth rate of $65.49 \%$. The purity of crude GlcN hydrochloride reached $92.02 \%$ (Supplementary data SD 1). From the experimental results, we concluded that the pretreatment of mycelium waste by SE was beneficial for the chemical extraction of GlcN. The main reason may be because SE pretreatment increased the mass ratio of chitin in the remaining solid.

Table 1: Effect of chemical extraction for materials treated by different SE pressures on GlcN hydrochloride yield.

\begin{tabular}{|c|c|c|c|c|c|}
\hline Pressure & Control & $1.0 \mathrm{MPa}$ & $1.5 \mathrm{MPa}$ & $2.0 \mathrm{MPa}$ & $2.5 \mathrm{MPa}$ \\
\hline $\begin{array}{l}\text { Weight of } \\
\text { GlcN hydrochloride } \llbracket g\end{array}$ & $0.09 \pm 0.01$ & $0.10 \pm 0.01$ & $0.11 \pm 0.01$ & $0.12 \pm 0.01$ & $0.15 \pm 0.01$ \\
\hline $\begin{array}{l}\text { Yield of } \\
\text { GlcN hydrochloride } \% \square\end{array}$ & $0.88 \pm 0.08$ & $1.01 \pm 0.08$ & $1.13 \pm 0.08$ & $1.21 \pm 0.12$ & $1.46 \pm 0.06$ \\
\hline Growth rate $[\% \square$ & I & $14.65 \pm 1.20$ & $28.40 \pm 3.87$ & $37.66 \pm 2.61$ & $65.49 \pm 8.14$ \\
\hline
\end{tabular}

\section{Effect of SE pretreatment on the release of soluble components}


The release of soluble components under different SE pressures was compared (Fig. 3 and Table 2), including total soluble sugar, total soluble protein, and total soluble solids. The content of all components increased continuously with the increase of pressure. Compared with the control, the content of total soluble sugar, total soluble protein, and total soluble solids increased to varying degrees (Fig. 3). The content of total soluble solids increased from $7.40 \mathrm{wt} \%$ to $28.60 \mathrm{wt} \%$ with a growth rate of $21.20 \%$. Higher SE pressure leads to greater degree of cell fragmentation and release of intracellular substances. This study is the first to apply SE to degrade the cell wall of mycelium waste.

Table 2: Comparative analysis of cellulolytic effect of various pretreatments of fermentation residue

\begin{tabular}{lllll}
\hline Classification & $\begin{array}{l}\text { Glucose } \\
(\mathrm{g} / \mathrm{L})\end{array}$ & $\begin{array}{l}\text { Arabinose } \\
(\mathrm{g} / \mathrm{L})\end{array}$ & $\begin{array}{l}\text { Cellobiose } \\
(\mathrm{g} / \mathrm{L})\end{array}$ & $\begin{array}{l}\text { Total sugars } \\
(\mathrm{g} / \mathrm{L})\end{array}$ \\
\hline Control & $2.39 \pm 0.18$ & $48.40 \pm 0.10$ & 0 & $50.79 \pm 0.24$ \\
$2.5 \mathrm{MPa}$ SE & $5.18 \pm 0.05$ & $50.64 \pm 0.10$ & $0.89 \pm 0.01$ & $56.71 \pm 0.16$ \\
IL & $3.15 \pm 0.04$ & $54.50 \pm 0.27$ & 0 & $57.66 \pm 0.25$ \\
$2.5 \mathrm{MPa}+\mathrm{IL}$ & $6.22 \pm 0.05$ & $57.18 \pm 0.09$ & $1.09 \pm 0.01$ & $64.49 \pm 0.09$ \\
& & & & \\
\hline
\end{tabular}

\section{Combined pretreatment of SE and IL for the enzymatic hydrolysis of mycelium waste}

SE was effective for the pretreatment of mycelium waste. Given that IL is widely applied in the pretreatment of cellulose and chitin, it is useful for studying the effect of comprehensive pretreatment on the utilization of mycelium waste. The pretreatment pressure of SE was set as $2.5 \mathrm{MPa}$ in accordance with the above data. According to the reported data, 1-butyl-3-methylimidazolium chloride ([Emim] [Cl]) is an IL with good effect on chitin dissolution [31,32], and the highest chitin solubility has been obtained with $3.5 \mathrm{wt} \%[\mathrm{Emim}][\mathrm{Cl}]$ at $110{ }^{\circ} \mathrm{C}[33]$. However, the chitin solubility is generally lower than $3 \mathrm{wt} \%$ in other ILs. Therefore, [Emim][CI] was employed in this study. Considering the following enzymatic hydrolysis, SE and IL were sequentially used for pretreatment of mycelium waste, and their effect was characterized. Cellulase and ReCDA were employed to release sugars and acetic acid, respectively.

\section{Effect of SE and IL pretreatment on the release of soluble sugars by cellulase}

Table 2 shows the sugar released from solid content by cellulase degradation with mycelium waste under different pretreatment conditions. Compared with the control, SE and IL pretreatment showed positive effect on the hydrolysis of cellulase toward mycelium waste. The concentrations of total sugar and single sugar, including glucose, arabinose, and cellobiose, increased obviously. When further pretreated by IL after SE, the concentration of total sugars increased to $64.49 \mathrm{~g} / \mathrm{L}(0.46 \mathrm{~g} / \mathrm{g}$ of sample) with a growth rate of $26.97 \%$ compared with the control. The maximum sugar yield was higher than that from distillers' dried grains with solubles $(0.38 \mathrm{~g} / \mathrm{g})[34]$.

\section{Application of by-products for ReCDA fermentation}


As stated above, the soluble substances released from SE pretreatment under $2.5 \mathrm{MPa}$ were rich in soluble sugar and proteins. Meanwhile, the solid content from SE could be further processed by IL pretreatment and enzymatic hydrolysis to yield fermentable sugars. On this basis, we used their mixtures as nutritional ingredients and added them into ReCDA media for ReCDA fermentation. After the preparation of ReCDA using the same experimental conditions, when $0.2 \mathrm{~g}$ residues was added into $100 \mathrm{~mL}$ media, the production of ReCDA exceeded the control after $30 \mathrm{~h}$ of fermentation, and the final product was approximately 1.5 -fold higher than that of the control (Fig. 4). This finding indicates that the addition of soluble components produced by SE pretreatment was beneficial for $R$. equi fermentation. One possible reason may be that the degradation products, especially the degradation products of chitin, released from $A$. Niger fermentation residue treated by SE and cellulase hydrolysis is conducive to the expression of ReCDA. As reported results, substances such as furfural, which can inhibit microbial fermentation, are produced during the SE treatment of cellulose [15, 35]. As Fig. 4, ReCDA fermentation was seriously inhibited with the addition of $0.4 \%$ residues, which might indicate that there are much inhibitors in the residues.

However, the content of sugar produced by enzymatic hydrolysis was not high. Two main reasons can explain this phenomenon. First, the raw material was sprayed for liquefaction at $0.1 \mathrm{MPa}$ before citric acid fermentation. Afterward, the material was treated with SE at low pressure, and further SE treatment did not exert much effect on corn fiber decomposition. Second, the amylase and glycosylase used in the production of citric acid had cellulase activity, and the corn fiber was hydrolyzed by cellulase to some extent.

\section{Effect of SE and IL pretreatment on the enzymatic deacetylation of chitin by ReCDA}

To investigate the effect of combined pretreatment on chitin recycling from mycelium waste, ReCDA was used to hydrolyze the solid content after sequential pretreatment. Table 3 shows the acetic acid content produced under different pretreatment conditions and the corresponding $A_{1560} / A_{1070}$ values of mycelium waste. The conditions include no pretreatment, SE pretreatment under $2.5 \mathrm{MPa}$, IL pretreatment and sequential pretreatment by SE and IL, and cellulase hydrolysis. Compared with IL pretreatment, SE pretreatment produced more acetic acid, indicating that it promotes the deacetylation of chitin. This finding is consistent with that of a previous report [18]. The changes of $A_{1560} / A_{1070}$ values of samples also demonstrate the occurrence of deacetylation, which was confirmed by XRD results (Supplementary data SD2). After deacetylation, two characteristic crystalline peaks of chitin and chitosan at $9^{\circ}-10^{\circ}$ and $19^{\circ}-20^{\circ}[36]$ changed remarkably or disappeared. The main reason may be that SE could break the crystal structure of chitin and promote the cracking and dissolution of chitin chain, which enhanced the deacetylation reaction due to more reactive sites exposed [28,37].

Table 3: Effect of enzymatic hydrolysis by CDA of various pretreatments of fermentation residue. 


\begin{tabular}{lll}
\hline Classification & $\begin{array}{l}\text { Acetic acid content } \\
\square \mathrm{mg} / \mathrm{LI}\end{array}$ & A1560/A1070 \\
\hline Control & 0 & 0.69 \\
$2.5 \mathrm{MPa}$ SE & $429.58 \pm 9.94$ & 0.57 \\
IL & 0 & 0.71 \\
$2.5 \mathrm{MPa}+\mathrm{IL}$ & $554.48 \pm 13.93$ & 0.55 \\
\hline
\end{tabular}

Noticeably, when combined pretreatments were employed, the acetic acid concentration was 1.3-fold higher than that produced by single SE pretreatment. FT-IR analysis showed the characteristic absorption peaks of the regenerated precipitate after enzymatic hydrolysis. This is similar to the standard chitosan (Supplementary data SD3). The result indicates that the combined pretreatment could improve the breakage of the crystalline region, which is beneficial for enzymatic hydrolysis $[10,38]$.

The scanning electron microscopy (SEM) results of samples treated by SE combined with IL showed that the structure of the materials became looser than that of other samples, which corresponds to the beneficial effect of enzymes (Supplementary data SD 4).

\section{Overall understanding and implications}

To our knowledge, no study has comprehensively utilized mycelium waste from citric acid fermentation. This study was therefore carried out through investigating the pretreatment methods and cascaded enzymatic hydrolysis on the waste. One part of pretreated products could be hydrolyzed for soluble sugars by cellulase, which could be used as nutrients for microorganisms. The other part, mycelia, could be used to produce chitin derivates, which is promoted by SE and IL pretreatment (Fig. 5).

Although a comprehensive utilization strategy of mycelium waste was proposed, the production cost and efficiency, especially the efficiency of ReCDA, are key issues that need to be considered before application. As shown in Table 3, ReCDA provided an acetic acid yield of $554.48 \mathrm{mg} / \mathrm{L}$ after $6 \mathrm{~h}$, which proved that pretreatment improved the efficiency of ReCDA. However, this value is too low to be considered for industrial application. Nevertheless, it is still worth studying because chitosan and GlcN from $A$. niger mycelia are important products with various advantages, such as continuous supply, free of heavy metals, and suitability for individuals with restrictive diets [39]. Thus, future large-scale studies should focus on the decrystallization of chitin by pretreatment and improvement of enzymatic hydrolysis involving chitinase and CDA [40-42].

\section{Conclusions}

In this study, SE was first employed for the pretreatment of mycelium waste from citric acid fermentation. The optimal pretreatment condition of SE was $2.5 \mathrm{MPa}$ for $1 \mathrm{~min}$. Combined with IL pretreatment, the 
enzymatic hydrolysis by cellulose increased by $26.97 \%$ after $24 \mathrm{~h}$, and CDA provided the highest acetic acid yield of $554.48 \mathrm{mg} / \mathrm{L}$ after $6 \mathrm{~h}$. The produced soluble sugars promoted the fermentation of ReCDA as ingredients. Hence, this study provided a sustainable technology for the comprehensive utilization of mycelium waste from citric acid fermentation.

\section{Materials And Methods}

\section{Materials}

The mycelium waste from citric acid fermentation used in this study was obtained from Weifang Ensign Industry Co., Ltd, China. The moisture content of a sample was adjusted to $30 \%$ before SE treatment. IL, [Emim][Cl], was purchased from Shanghai Macklin Biochemical Co., Ltd., China. Standard sample of GlcN hydrochloride was obtained from Nantong Foreign Trade Medicine and Health Products Co., Ltd. CDAproducing strain, Rhodococcus equi CGMCC14861 (ReCDA), was stored by the China General Microbiological Culture Collection Center.

\section{SE pretreatment of mycelium waste from citric acid fermentation}

SE pretreatment was conducted in an explosion device composed of a $5 \mathrm{~L}$ reaction chamber, a steam generator, and a sample collector. During the SE pretreatment process, only high-pressure steam was pushed into the reaction chamber to control the reaction pressure. After 1 min treatment, the samples were suddenly discharged into the collector. Samples were collected for further analysis and characterization.

\section{Sequential pretreatment of SE and IL toward mycelium waste from citric acid fermentation}

When combined pretreatment was performed, $0.5 \mathrm{~g}$ of different pretreated materials by SE was added into $10 \mathrm{~g}$ of [Emim] [Cl], and the mixture was heated at $100^{\circ} \mathrm{C}$ for $6 \mathrm{~h}$ [43]. Then, samples were thoroughly washed with distilled water, and the solid residues were recovered by filtration and freeze drying. The supernatant containing IL and water was kept for recycling [44].

\section{Changes in structure and morphological properties of mycelium waste after pretreatment}

Residues obtained after various pretreatments were characterized using SEM, FT-IR spectroscopy, and XRD. Materials treated with SE were covered with gold before being observed using a SU1510 FE-SEM (Hitachi, Japan). SEM was conducted in accordance with a previously reported method with slight modifications [45]. For FT-IR spectroscopy, samples were scanned with an IS50 spectrometer (Nicolet, USA) at a range of $4000 \mathrm{~cm}^{-1}$ to $400 \mathrm{~cm}^{-1}$ and resolution of $4 \mathrm{~cm}^{-1}$ [46]. XRD was performed in accordance with a previously reported method with slight modifications [47]. Samples were analyzed using a D8 Advance diffractometer (Brucker, Germany), with incident radiation CuKa $(\lambda=1.54)$ at voltage of $36 \mathrm{kV}$ and current of $20 \mathrm{~mA}$. The range of investigation corresponded to $5^{\circ}<2 \theta<60^{\circ}$ with a step scan 
of $0.02^{0}$ at a scan rate of $4^{\circ} / \mathrm{min}$. The pore size distribution of samples was analyzed using a specific surface and aperture analyzer (3H-2000PS1/2, Beishide Instrument-S\&T. (Beijing) Co., Ltd.).

\section{Composition analysis of mycelium waste after pretreatment}

The contents of total soluble sugars and total soluble proteins were determined in accordance with the protocols described by Dubois et al. [48] and Bradford [49], respectively. Total soluble solids were determined by gravimetric method. Samples were washed with deionized water until the total soluble sugar was not detected. Then, they were dried at $65^{\circ} \mathrm{C}$ for $10-12 \mathrm{~h}$ to constant weight, weighed, and used to calculate the content of total soluble solids. Analysis of glucose, arabinose, and cellobiose was conducted by high-performance liquid chromatography (HPLC) following a previously reported method [34].

\section{Chemical preparation of GICN hydrochloride from mycelium waste}

In accordance with a previously reported method [39], $10 \mathrm{~g}$ of samples treated at different pressures and dried at $65^{\circ} \mathrm{C}$ for $10-12 \mathrm{~h}$ to constant weight was added to $25 \mathrm{~mL}$ of hydrochloric acid (30\%), incubated at $90^{\circ} \mathrm{C}$ for $2 \mathrm{~h}$, and filtered [50]. The filtrate was collected, dried to constant weight, and weighed for calculating the yield of crude GlcN hydrochloride.

\section{Enzymatic hydrolysis by cellulase toward pretreated mycelium waste}

Mycelium waste pretreated after combined pretreatment was hydrolyzed by cellulase in accordance with a previously reported method with slight modification (Pielhop et al. 2016). Samples (140 g/L) were incubated in a shaker at $50^{\circ} \mathrm{C}$ and $210 \mathrm{rpm}$ for $24 \mathrm{~h}$ and then analyzed for sugars in the supernatant.

\section{Enzymatic preparation of chitosan by CDA from pretreated mycelium waste}

CDA produced by ReCDA was used for the deacetylation of mycelium waste. To prepare ReCDA, the producing strain was cultivated on Luria Bertani medium at $37^{\circ} \mathrm{C}$ and $200 \mathrm{rpm}$ for $24 \mathrm{~h}$. The bacterial cells were washed and diluted with $0.2 \mathrm{M}$ phosphate buffer $(\mathrm{pH} 7.0)$ and then homogenized by grinding with liquid nitrogen in a mortar. The enzyme activity assay of crude CDA was mainly performed as described previously [51]. One unit of CDA activity was defined as the amount of enzyme that catalyzes the release of 4-nitroaniline per hour from 4-nitroacetanilide.

Approximately $0.1 \mathrm{~g}$ of untreated and pretreated samples was added into $5 \mathrm{~mL}$ of crude ReCDA, stirred evenly, and subjected to vibration reaction under $37^{\circ} \mathrm{C}$ for $6 \mathrm{~h}$. Samples were immediately boiled for 5 min and filtered. Then, the production of acetic acid in the liquid was analyzed by HPLC [52, 53]. The solids were freeze-dried and detected by FT-IR spectroscopy to analyze the deacetylation degree (DD) [29].

\section{Abbreviations}


GIcN: glucosamine; IL: ionic liquid; ReCDA: chitin deacetylase from Rhodococcus equi; A. niger. Aspergillus niger; GIcNAc: N-acetyl-D-glucosamine; CDA: chitin deacetylase; SE: steam explosion; [Emim] [CI]: 1-butyl-3-methylimidazolium chloride; SEM: scanning electron microscopy; FT-IR: Fourier-transform infrared; XRD: spectroscopy, and X-ray diffraction; HPLC: high-performance liquid chromatography; DD: deacetylation degree.

\section{Declarations}

\section{Acknowledgements}

We are grateful to Mr. Chuanhui Zhang for his technical assistance.

\section{Authors' contributions}

QYM and XZG performed research, analyzed data, and wrote the paper. XYB, MMP and YPY performed research. MLX and QH analyzed the data and provided technical assistance. MW designed research. YBS designed research, analyzed data, and wrote the paper. All authors read and approved the final manuscript.

\section{Funding}

This work was financially supported by the National Natural Science Foundation of China (grant no. 21978221, 21706194), Tianjin Municipal Science and Technology Commission (17PTGCCX00190, 17PTSYJC00080), the Innovative Research Team of Tianjin Municipral Education Commision (TD135013).

\section{Availability of supporting data}

All data supporting the conclusions of this article are included within the manuscript and additional files.

\section{Ethics approval and consent to participate}

Not applicable.

\section{Consent for publication}

All authors provide their consent for publication of their manuscript in Biotechnology for Biofuels.

\section{Competing interests}

The authors declare that they have no competing interests.

\section{Author details}


${ }^{1}$ Key Laboratory of Industrial Fermentation Microbiology (Tianjin University of Science \&Technology), Ministry of Education, Tianjin Key Lab of Industrial Microbiology, College of Biotechnology, Tianjin University of Science and Technology, Tianjin 300457, P. R. China. ${ }^{2}$ School of Life Science, Shandong University of Technology, Zibo 255049, China. ${ }^{3}$ School of Science, College of Science, Engineering and Health, RMIT University, Melbourne, VIC, Australia

\section{References}

1. Steiger MG, Mattanovich D, Sauer M: Microbial organic acid production as carbon dioxide sink. Fems Microbiology Letters 2017, 364(21).

2. Wu T, Zivanovic S, Draughon FA, Conway WS, Sams CE: Physicochemical properties and bioactivity of fungal chitin and chitosan. J Agric Food Chem 2005, 53(10):3888-3894.

3. Suntornsuk W, Pochanavanich P, Suntornsuk L: Fungal chitosan production on food processing byproducts. Process Biochemistry 2002, 37(7):727-729.

4. Pochanavanich $\mathrm{P}$, Suntornsuk W: Fungal chitosan production and its characterization. Letters in Applied Microbiology 2002, 35(1):17-21.

5. Ghormade V, Pathan EK, Deshpande MV: Can fungi compete with marine sources for chitosan production? International Journal of Biological Macromolecules.

6. Nidheesh T, Gaurav Kumar P, Suresh PV: Enzymatic degradation of chitosan and production of dglucosamine by solid substrate fermentation of exo- $\beta$-d-glucosaminidase (exochitosanase) by Penicillium decumbens CFRNT15. International Biodeterioration \& Biodegradation 2015, 97:97-106.

7. Zhang A, Gao C, Wang J, Chen K, Ouyang P: An efficient enzymatic production of N-acetyl-Dglucosamine from crude chitin powders. Green Chemistry 2016, 18(7):2147-2154.

8. Cai J, Yang J, Du Y, Fan L, Qiu Y, Li J, Kennedy JF: Enzymatic preparation of chitosan from the waste Aspergillus niger mycelium of citric acid production plant. Carbohydrate Polymers 2006, 64(2):151157.

9. John M, Röhrig H, Schmidt J, Wieneke U, Schell J: Rhizobium NodB protein involved in nodulation signal synthesis is a chitooligosaccharide deacetylase. Proceedings of the National Academy of Sciences 1993, 90(2):625-629.

10. Aspras I, Jaworska MM, Górak A: Kinetics of chitin deacetylase activation by the ionic liquid [Bmim] [Br]. Journal of Biotechnology 2017, 251:94-98.

11. Pillai CKS, Paul W, Sharma CP: Chitin and chitosan polymers: Chemistry, solubility and fiber formation. Progress in Polymer Science 2009, 34(7):641-678.

12. Villa-Lerma G, González-Márquez H, Gimeno M, Trombotto S, David L, Ifuku S, Shirai K: Enzymatic hydrolysis of chitin pretreated by rapid depressurization from supercritical 1,1,1,2-tetrafluoroethane toward highly acetylated oligosaccharides. Bioresource Technology 2016, 209:180-186.

13. Montipó S, Ballesteros I, Fontana RC, Liu S, Martins AF, Ballesteros M, Camassola M: Integrated production of second generation ethanol and lactic acid from steam-exploded elephant grass. 
Bioresource Technology 2018, 249:1017-1024.

14. Matsakas L, Nitsos C, Raghavendran V, Yakimenko O, Persson G, Olsson E, Rova U, Olsson L, Christakopoulos P: A novel hybrid organosolv: steam explosion method for the efficient fractionation and pretreatment of birch biomass. Biotechnology for Biofuels 2018, 11(1):160.

15. Carvalho AFA, Marcondes WF, de Oliva Neto P, Pastore GM, Saddler JN, Arantes V: The potential of tailoring the conditions of steam explosion to produce xylo-oligosaccharides from sugarcane bagasse. Bioresource Technology 2018, 250:221-229.

16. Taherzadeh MJ, Karimi K: Pretreatment of lignocellulosic wastes to improve ethanol and biogas production: a review. International journal of molecular sciences 2008, 9(9):1621-1651.

17. Mulat DG, Huerta SG, Kalyani D, Horn SJ: Enhancing methane production from lignocellulosic biomass by combined steam-explosion pretreatment and bioaugmentation with cellulolytic bacterium Caldicellulosiruptor bescii. Biotechnology for Biofuels 2018, 11(1):19.

18. Villa-Lerma G, González-Márquez H, Gimeno M, López-Luna A, Bárzana E, Shirai K: Ultrasonication and steam-explosion as chitin pretreatments for chitin oligosaccharide production by chitinases of Lecanicillium lecanii, vol. 146; 2013.

19. Perez-Pimienta JA, Lopez-Ortega MG, Chavez-Carvayar JA, Varanasi P, Stavila V, Cheng G, Singh S, Simmons BA: Characterization of agave bagasse as a function of ionic liquid pretreatment. Biomass Bioenergy 2015, 75:180-188.

20. Raj T, Gaur R, Dixit P, Gupta RP, Kagdiyal V, Kumar R, Tuli DK: Ionic liquid pretreatment of biomass for sugars production: Driving factors with a plausible mechanism for higher enzymatic digestibility. Carbohydrate Polymers 2016, 149:369-381.

21. Mate DM, Alcalde M: Laccase engineering: From rational design to directed evolution. Biotechnology Advances 2015, 33(1):25-40.

22. Patel R, Kumari M, Khan AB: Recent Advances in the Applications of lonic Liquids in Protein Stability and Activity: A Review. Applied Biochemistry and Biotechnology 2014, 172(8):3701-3720.

23. Salihu A, Alam MZ: Solvent tolerant lipases: A review. Process Biochemistry 2015, 50(1):86-96.

24. Singh S, Varanasi P, Singh P, Adams PD, Auer M, Simmons BA: Understanding the impact of ionic liquid pretreatment on cellulose and lignin via thermochemical analysis. Biomass Bioenergy 2013, 54:276-283.

25. Wang B, Li H, Zhu L, Tan F, Li Y, Zhang L, Ding Z, Shi G: High-efficient production of citric acid by Aspergillus niger from high concentration of substrate based on the staged-addition glucoamylase strategy. Bioprocess Biosystems Eng 2017, 40(6):891-899.

26. Barl B, Biliaderis CG, Murray ED, Macgregor AW: Combined chemical and enzymic treatments of corn husk lignocellulosics. Journal of the Science of Food and Agriculture 1991, 56(2):195-214.

27. Auxenfans T, Crônier D, Chabbert B, Paës G: Understanding the structural and chemical changes of plant biomass following steam explosion pretreatment. Biotechnology for Biofuels 2017, 10(1):36. 
28. Liu TG, Li B, Huang W, Lv B, Chen J, Zhang JX, Zhu LP: Effects and kinetics of a novel temperature cycling treatment on the N-deacetylation of chitin in alkaline solution. Carbohydrate Polymers 2009, 77(1):110-117.

29. Shimo M, Abe M, Ohno H: Functional Comparison of Polar lonic Liquids and Onium Hydroxides for Chitin Dissolution and Deacetylation to Chitosan. ACS Sustainable Chemistry \& Engineering 2016, 4(7):3722-3727.

30. Shigemasa Y, Matsuura H, Sashiwa H, Saimoto H: Evaluation of different absorbance ratios from infrared spectroscopy for analyzing the degree of deacetylation in chitin. International Journal of Biological Macromolecules 1996, 18(3):237-242.

31. Xie H, Zhang S, Li S: Chitin and chitosan dissolved in ionic liquids as reversible sorbents of $\mathrm{CO} 2$. Green Chemistry 2006, 8(7):630-633.

32. Shamshina JL: Chitin in ionic liquids: historical insights into the polymer's dissolution and isolation. A review. Green Chemistry 2019, 21(15):3974-3993.

33. Jaworska MM, Gorak A: Modification of chitin particles with chloride ionic liquids. Materials Letters 2016, 164:341-343.

34. Iram A, Cekmecelioglu D, Demirci A: Optimization of dilute sulfuric acid, aqueous ammonia, and steam explosion as the pretreatments steps for distillers' dried grains with solubles as a potential fermentation feedstock. Bioresource Technology 2019, 282:475-481.

35. Hu F, Jung S, Ragauskas A: Pseudo-lignin formation and its impact on enzymatic hydrolysis. Bioresource Technology 2012, 117:7-12.

36. Yen M-T, Yang J-H, Mau J-L: Physicochemical characterization of chitin and chitosan from crab shells, vol. 75; 2009.

37. Liu C, Wang G, Sui W, An L, Si C: Preparation and Characterization of Chitosan by a Novel Deacetylation Approach Using Glycerol as Green Reaction Solvent. ACS Sustainable Chemistry \& Engineering 2017, 5(6):4690-4698.

38. Husson E, Hadad C, Huet G, Laclef S, Lesur D, Lambertyn V, Jamali A, Gottis S, Sarazin C, Nguyen Van Nhien A: The effect of room temperature ionic liquids on the selective biocatalytic hydrolysis of chitin via sequential or simultaneous strategies. Green Chemistry 2017, 19(17):4122-4131.

39. Ma Q, Gao X: Categories and biomanufacturing methods of glucosamine. Applied Microbiology and Biotechnology 2019:1-7.

40. Giuliano Garisto Donzelli B, Ostroff G, Harman GE: Enhanced enzymatic hydrolysis of langostino shell chitin with mixtures of enzymes from bacterial and fungal sources. Carbohydrate Research 2003, 338(18):1823-1833.

41. Sinha S, Kumar R, Dhakate SR, Chand S: Chitosanase Linked PAN nanofibres for enzymatic production of glucosamine. International Journal of Bioscience, Biochemistry and Bioinformatics 2011, 1(2):153-158.

42. Setthakaset P, Pichyangkura R, Ajavakom A, Sukwattanasinitt M: Preparation of N-acetyl-DGlucosamine using enzyme from Aspergillus sp. Journal of Metals, Materials and Minerals 2008, 
18(2):53-57.

43. Qin Y, Lu X, Sun N, Rogers RD: Dissolution or extraction of crustacean shells using ionic liquids to obtain high molecular weight purified chitin and direct production of chitin films and fibers. Green Chemistry 2010, 12(6):968.

44. Hou X, Wang Z, Sun J, Li M, Wang S, Chen K, Gao Z: A microwave-assisted aqueous ionic liquid pretreatment to enhance enzymatic hydrolysis of Eucalyptus and its mechanism. Bioresource Technology 2019, 272:99-104.

45. Padrino B, Lara-Serrano M, Morales-delaRosa S, Campos-Martín JM, Fierro JLG, Martínez F, Melero JA, Puyol D: Resource Recovery Potential From Lignocellulosic Feedstock Upon Lysis With Ionic Liquids. Frontiers in bioengineering and biotechnology 2018, 6:119-119.

46. Nargotra P, Sharma V, Gupta M, Kour S, Bajaj BK: Application of ionic liquid and alkali pretreatment for enhancing saccharification of sunflower stalk biomass for potential biofuel-ethanol production. Bioresource Technology 2018, 267:560-568.

47. Ngo THD, Ngo DN: Effects of low-frequency ultrasound on heterogenous deacetylation of chitin. International Journal of Biological Macromolecules 2017, 104:1604-1610.

48. DuBois M, Gilles KA, Hamilton JK, Rebers PA, Smith F: Colorimetric Method for Determination of Sugars and Related Substances. Anal Chem 1956, 28(3):350-356.

49. Bradford MM: A rapid and sensitive method for the quantitation of microgram quantities of protein utilizing the principle of protein-dye binding. Analytical Biochemistry 1976, 72(1):248-254.

50. Mojarrad JS, Nemati M, Valizadeh H, Ansarin M, Bourbour S: Preparation of glucosamine from exoskeleton of shrimp and predicting production yield by response surface methodology. Journal of agricultural and food chemistry 2007, 55(6):2246-2250.

51. Sun Y, Zhang J, Wu S, Wang S: Statistical optimization for production of chitin deacetylase from Rhodococcus erythropolis HG05. Carbohydrate Polymers 2014, 102:649-652.

52. Naqvi S, Cord-Landwehr S, Singh R, Bernard F, Kolkenbrock S, El Gueddari NE, Moerschbacher BM: A recombinant fungal chitin deacetylase produces fully defined chitosan oligomers with novel patterns of acetylation. Applied and Environmental Microbiology 2016, 82(22):6645-6655.

53. Amorim RVS, Ledingham WM, Fukushima K, Campos-Takaki GM: Screening of chitin deacetylase from Mucoralean strains (Zygomycetes) and its relationship to cell growth rate. Journal of Industrial Microbiology and Biotechnology 2005, 32(1):19-23.

\section{Figures}




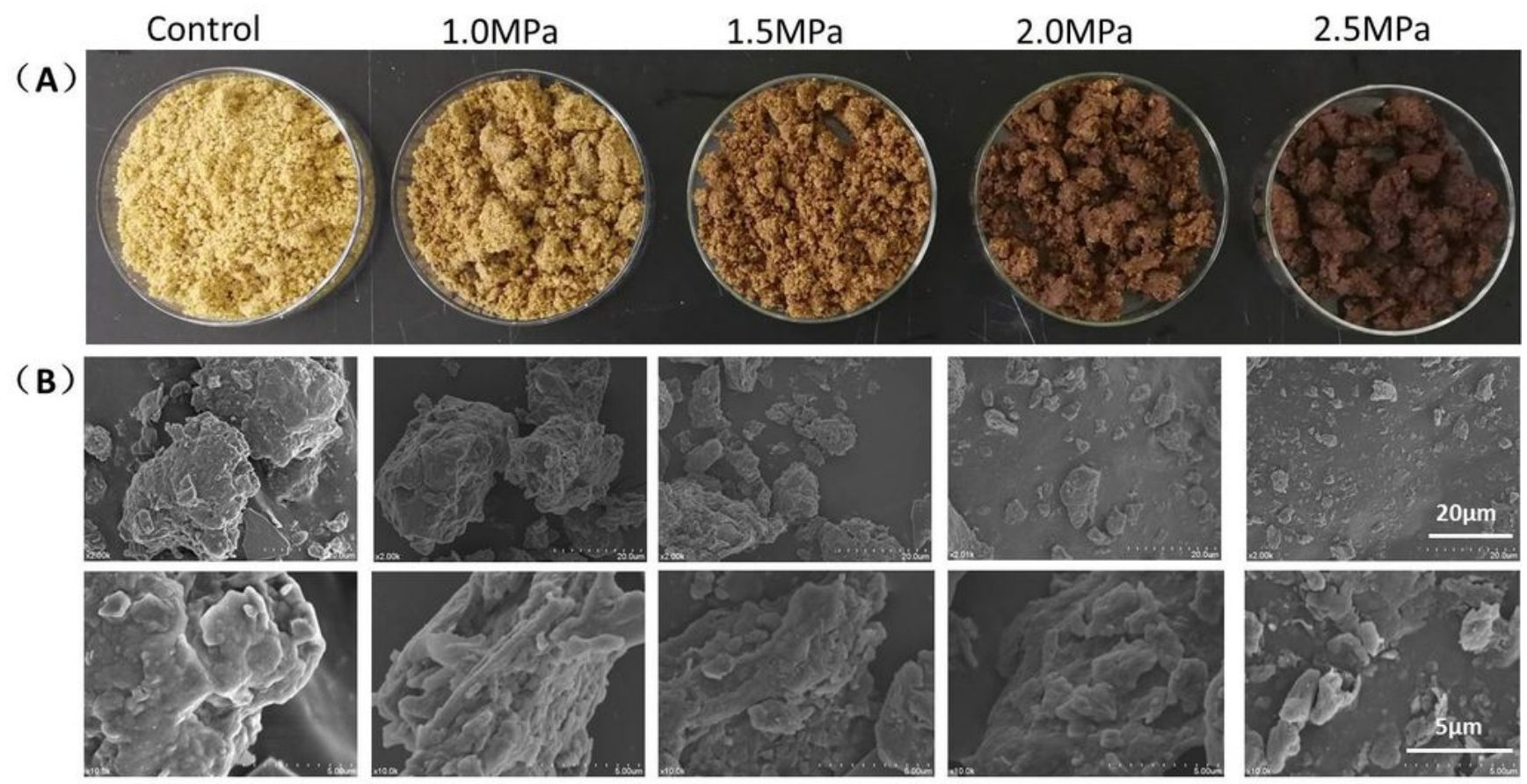

(C)

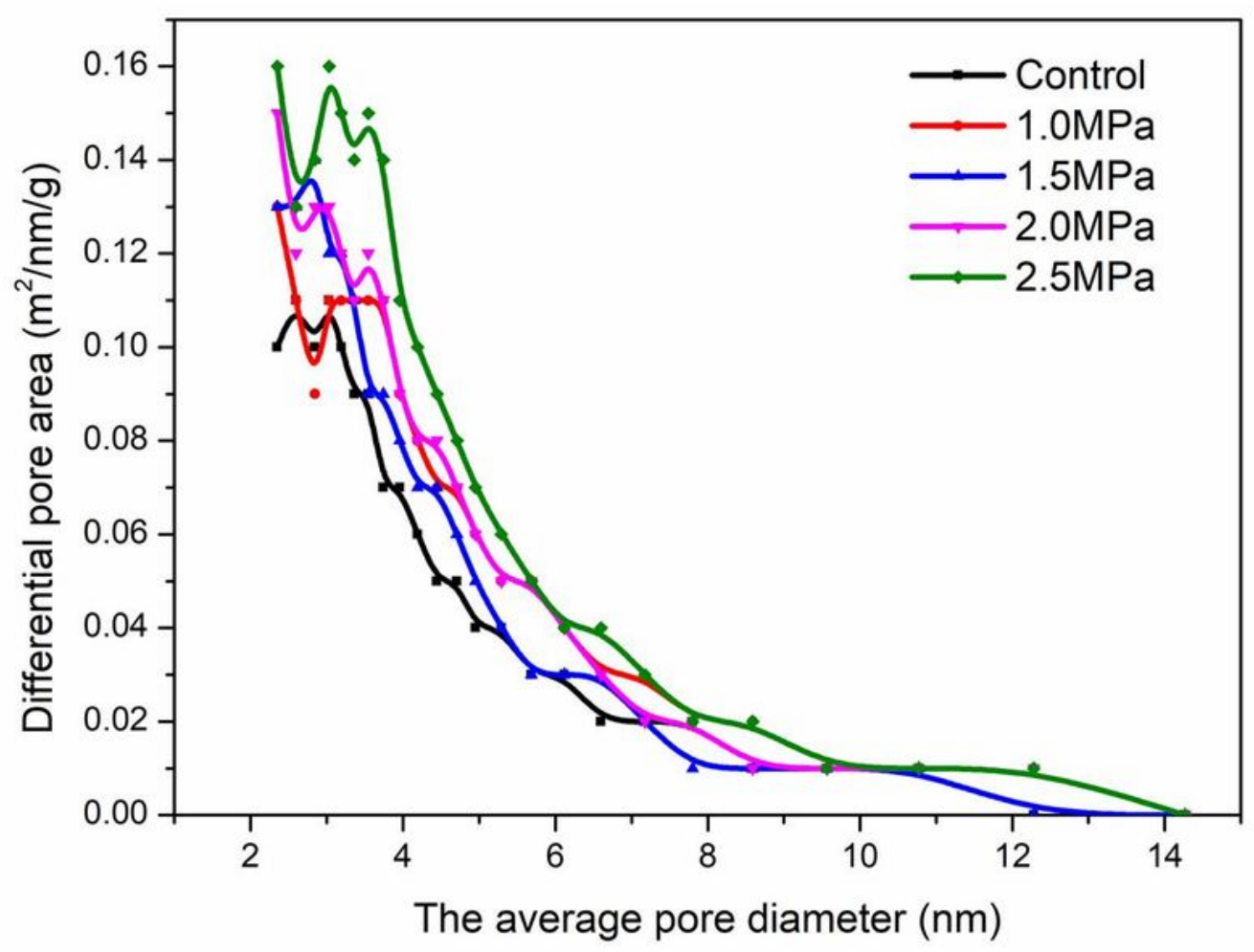

Figure 1

SEM images ( $A$ and $B$ ) and analysis of pore size distribution (C) of various pretreatments of fermentation residue. 
(A)

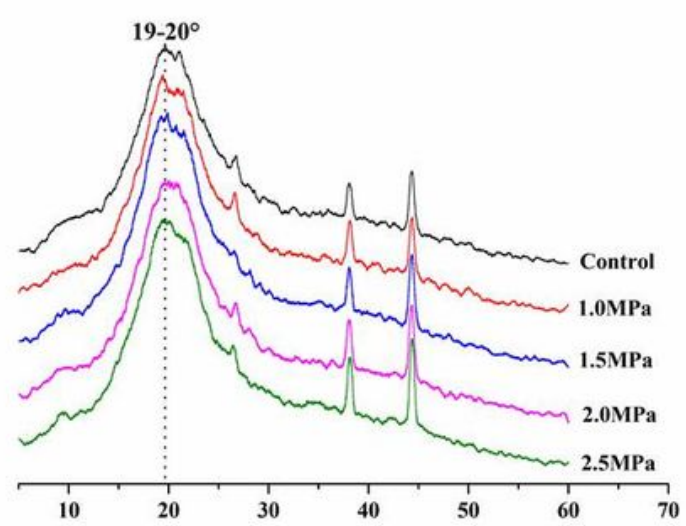

(B)

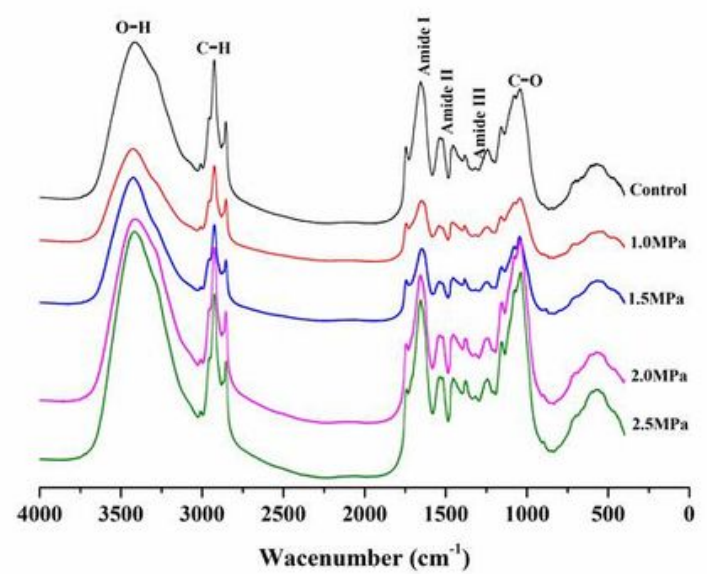

(C)

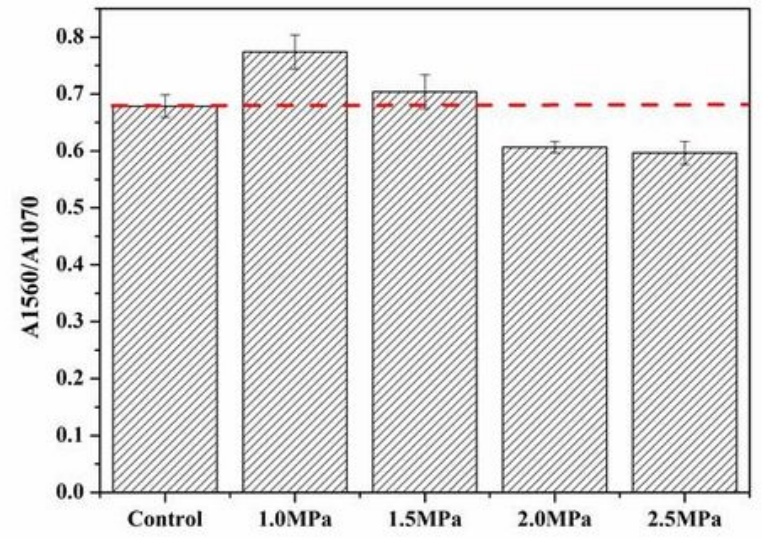

Figure 2

XRD (A) and FT-IR (B and C) analysis of various pretreatments of fermentation residue. 


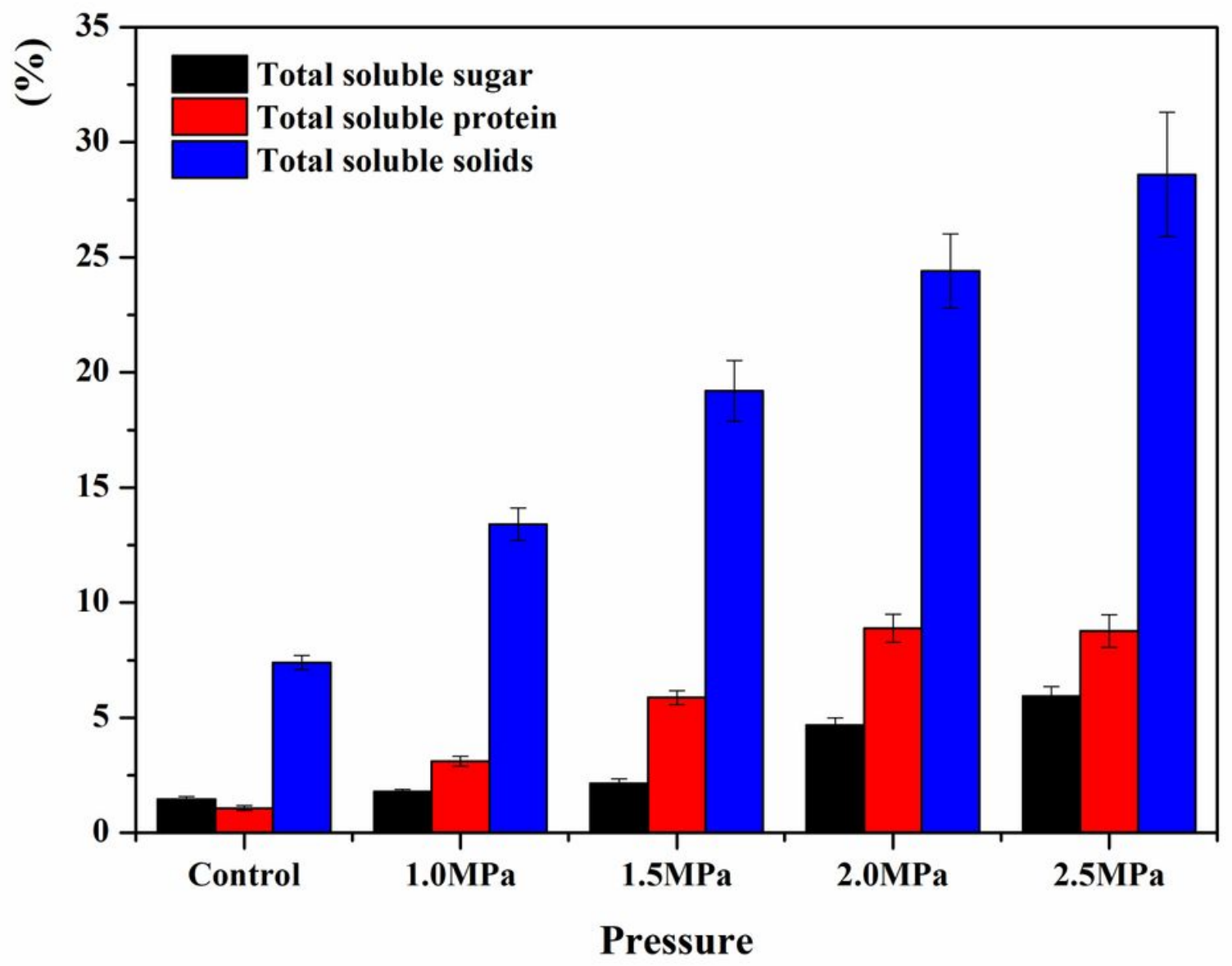

Figure 3

Comparison of soluble components of various pretreatments of fermentation residue. 


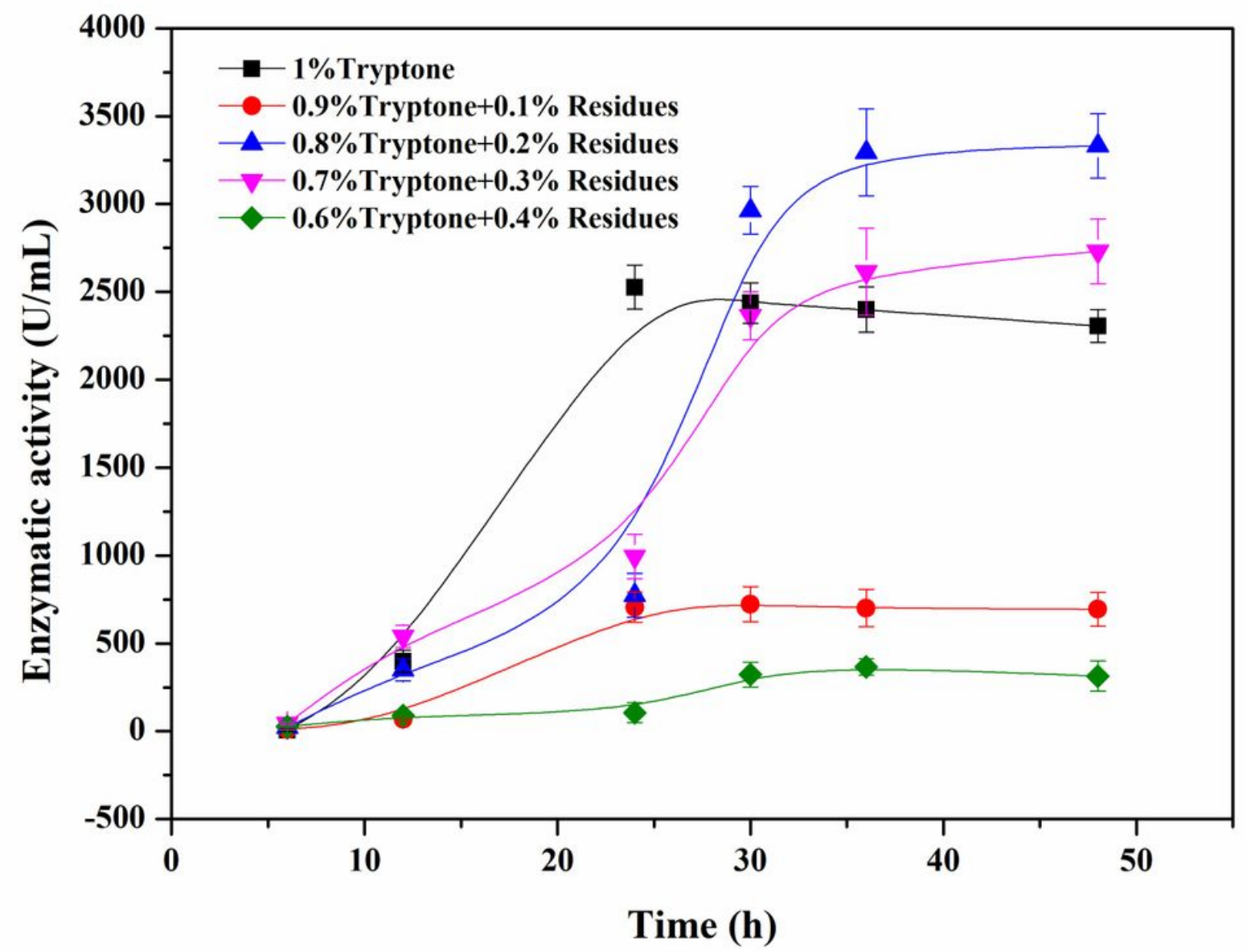

Figure 4

CDA fermentation in different media containing residue pretreated by SE and cellulolytic hydrolysis.

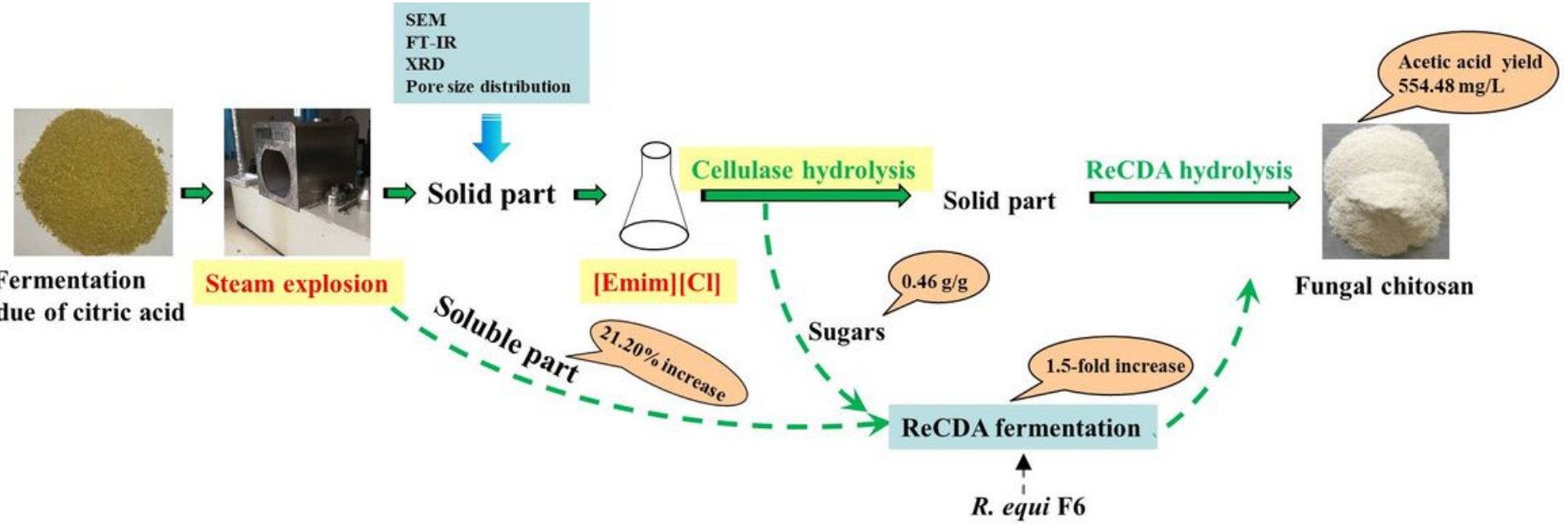

Figure 5 
Comprehensive utilization of A. niger mycelium waste from citric acid fermentation on the basis of SE and IL pretreatment

\section{Supplementary Files}

This is a list of supplementary files associated with this preprint. Click to download.

- ElectronicSupplementarylnformation.docx 